\title{
Reliability, validity and discriminant ability of a robotic device for finger training in patients with subacute stroke
}

Marco Germanotta ${ }^{1 *}$ D, Valerio Gower ${ }^{2}$, Dionysia Papadopoulou ${ }^{2}$, Arianna Cruciani ${ }^{2}$, Cristiano Pecchioli ${ }^{2}$, Rita Mosca ${ }^{2}$, Gabriele Speranza ${ }^{2}$, Catuscia Falsini ${ }^{1}$, Francesca Cecchi ${ }^{1}$, Federica Vannetti ${ }^{1}$, Angelo Montesano ${ }^{2}$, Silvia Galeri' ${ }^{2}$, Furio Gramatica ${ }^{2}$, Irene Aprile ${ }^{2}$ and the FDG Robotic Rehabilitation Group

\begin{abstract}
Background: The majority of stroke survivors experiences significant hand impairments, as weakness and spasticity, with a severe impact on the activity of daily living. To objectively evaluate hand deficits, quantitative measures are needed. The aim of this study is to assess the reliability, the validity and the discriminant ability of the instrumental measures provided by a robotic device for hand rehabilitation, in a sample of patients with subacute stroke.

Material and methods: In this study, 120 patients with stroke and 40 controls were enrolled. Clinical evaluation included finger flexion and extension strength (using the Medical Research Council, MRC), finger spasticity (using the Modified Ashworth Scale, MAS) and motor control and dexterity during ADL performance (by means of the Frenchay Arm Test, FAT). Robotic evaluations included finger flexion and extension strength, muscle tone at rest, and instrumented MAS and Modified Tardieu Scale. Subjects were evaluated twice, one day apart, to assess the test-retest reliability of the robotic measures, using the Intraclass Correlation Coefficient (ICC). To estimate the response stability, the standard errors of measurement and the minimum detectable change (MDC) were also calculated. Validity was assessed by analyzing the correlations between the robotic metrics and the clinical scales, using the Spearman's Correlation Coefficient ( $r$ ). Finally, we investigated the ability of the robotic measures to distinguish between patients with stroke and healthy subjects, by means of Mann-Whitney $U$ tests.

Results: All the investigated measures were able to discriminate patients with stroke from healthy subjects ( $p<$ 0.001). Test-retest reliability was found to be excellent for finger strength (in both flexion and extension) and muscle tone, with ICCs higher than 0.9. MDCs were equal to $10.6 \mathrm{~N}$ for finger flexion, $3.4 \mathrm{~N}$ for finger extension, and $14.3 \mathrm{~N}$ for muscle tone. Conversely, test-retest reliability of the spasticity measures was poor. Finally, finger strength (in both flexion and extension) was correlated with the clinical scales ( $r$ of about 0.7 with MRC, and about 0.5 with FAT).

Discussion: Finger strength (in both flexion and extension) and muscle tone, as provided by a robotic device for hand rehabilitation, are reliable and sensitive measures. Moreover, finger strength is strongly correlated with clinical scales. Changes higher than the obtained MDC in these robotic measures could be considered as clinically relevant and used to assess the effect of a rehabilitation treatment in patients with subacute stroke.
\end{abstract}

Keywords: Stroke, Hand, Rehabilitation, Upper extremity, Robotics, Reliability, Validity, Discriminant ability

\footnotetext{
*Correspondence: mgermanotta@dongnocchi.it

'IRCCS Fondazione Don Carlo Gnocchi, Via di Scandicci, 269, 50143 Florence,

Italy

Full list of author information is available at the end of the article
}

(C) The Author(s). 2019 Open Access This article is distributed under the terms of the Creative Commons Attribution 4.0 International License (http://creativecommons.org/licenses/by/4.0/), which permits unrestricted use, distribution, and reproduction in any medium, provided you give appropriate credit to the original author(s) and the source, provide a link to the Creative Commons license, and indicate if changes were made. The Creative Commons Public Domain Dedication waiver (http://creativecommons.org/publicdomain/zero/1.0/) applies to the data made available in this article, unless otherwise stated. 


\section{Background}

After stroke, most of the patients experiences a deficit at the hand and, six months after the acute event, about $65 \%$ of patients cannot incorporate the affected hand into their usual activities [1]. The ability to perform activities of daily living (ADL) is highly dependent on hand function, leaving those suffering with hand impairments less capable of executing ADL and consequently with a reduced quality of life [2]. Grip, strength, and overall functions of the hands are often impaired, making everyday tasks hard to accomplish and consequently compromising severely the ability to be independent in functional activities. In severe patients, the injured hand very often remains plegic, with difficulty extending the fingers [3] and no marked recovery over time $[4,5]$, making the recovery of hand function one of the most challenging topics in stroke rehabilitation [6].

Rehabilitation of arm function after stroke has been changing substantially over the last decades [7] but, up to now, the optimal intervention is far from being identified. In the last decades, a growing interest has been addressed towards the use of robotic devices to treat the upper limb in patients suffering from neurological disease, especially stroke [8]. In fact, these devices allow to increase of the amount and intensity of the therapy, to standardize the treatment, providing a complex but controlled multisensory stimulation $[9,10]$ and helping the patient to complete the required task while preventing inappropriate movements [11]. Even if most of the robots focuses on the more proximal joints (shoulder and elbow) [12], some devices have been specifically developed to target the hand, using either end-effector [13-15] or exoskeleton $[16,17]$ design, with encouraging results in terms of motor recovery [12, 18-22].

In addition, robotic devices, because of their built-in technology in terms of sensors and actuators, are able to objectively quantify the motor status of patients after brain damage, as well as their motor recovery. In fact, such devices are able to acquire kinematic and kinetic data which are processed to obtain quantitative indices [23-34]. These robot-derived measures can potentially add meaningful information about the patient's performance, helping the clinicians in patient's assessment. As a condition of their use in clinical practice, however, their properties in terms of reliability, validity and responsiveness should be assessed. In fact, in order to be brought into the clinical field, the obtained measures have to be stable, sensitive and clinically meaningful.

Amadeo (Tyromotion, Austria) is a mechatronic endeffector robotic device specifically designed to treat the hand. Results from its application in stroke patients suggest its efficacy in reducing hand impairment $[20,22,35,36]$. To the best of our knowledge, however, the psychometric properties of the measures provided by this robotic device have not yet been investigated. Therefore, the aim of the present work is to evaluate, within a multicenter randomized controlled trial, the reliability, the concurrent validity and the discriminant ability of the indices provided by a robotic rehabilitation device for hand rehabilitation.

\section{Materials and methods \\ Participants}

In this study, we analyzed the data obtained from 120 consecutive patients with subacute stroke, enrolled in 6 different rehabilitation centers of the Fondazione Don Carlo Gnocchi (Rome, Milan, Florence, Sant'Angelo dei Lombardi, Rovato and Fivizzano) This is a crosssectional analysis of baseline data collected as part of a larger clinical trial [37], approved by the institutional ethics committee (FDG_6.4.2016) and registered at clinicaltrials.gov with identifier number NCT02879279.

Inclusion criteria were: (1) first-ever stroke (cerebral infarction or hemorrhage), confirmed by either brain CT or MRI findings (2) age between 40 and 85 years; (3) time since stroke onset less or equal to 6 months; (4) cognitive and language abilities sufficient to understand the experiments and follow instructions. Exclusion criteria were: (1) upper extremity Fugl-Meyer score $>58$; (2) behavioral and cognitive disorders and/or reduced compliance that would interfere with active therapy; (3) fixed contraction deformity in the affected limb that would interfere with active therapy (ankylosis, Modified Ashworth Scale $=4$ ); (4) inability to discriminate distinctly the images showed on a monitor placed at the eye level of each subject at a distance of about $50 \mathrm{~cm}$, even with corrective glasses. Demographic and characteristics of the patients are shown in Table 1. In addition, 40 age and sex matched subjects without neurological or other relevant medical conditions served as a reference population. All participants gave their written informed consent according to the Declaration of Helsinki.

Table 1 Demographic and clinical characteristics of the sample

\begin{tabular}{|c|c|}
\hline & Patients with stroke $(N=120)$ \\
\hline Age (years) & $69.4(10.7)$ \\
\hline $\operatorname{Sex}(M / F)$ & $68 / 52$ \\
\hline Ischemic/Hemorragic & $95 / 25$ \\
\hline Time since stroke (days) & $48.2(43.7)$ \\
\hline Fugl-Meyer Assessment - Upper Extremity & $24.3(16.5)$ \\
\hline Proximal & $11.7(8.2)$ \\
\hline Wrist/hand & $9.2(8.1)$ \\
\hline Coordination/speed & $3.4(1.3)$ \\
\hline MRC finger extension & $1.6(1.6)$ \\
\hline MRC finger flexion & $1.4(1.6)$ \\
\hline Frenchay Arm Test & $1.1(1.8)$ \\
\hline MAS (fingers) & $0.4(0.8)$ \\
\hline
\end{tabular}

Data are mean (SD), or numbers 


\section{Clinical assessment}

Patients were clinically evaluated using the Medical Research Council (MRC) [38], the Modified Ashworth Scale (MAS) [39] and the Frenchay Arm test (FAT) [40]. The MRC is an ordinal scale for muscle power, ranging from 0 to 5 in relation to the maximum expected for that muscle; in the present work, we evaluated finger flexor and finger extensor. The MAS is an ordinal scale used for grading the resistance encountered during passive muscle stretching, ranging from 0 (normal muscle tone) up to 4 (limb rigid in flexion or extension). The FAT is a measure of upper extremity proximal motor control and dexterity during ADL performance in patients with impairments resulting from neurological conditions, ranging from 0 (worse) to 5 (best). Clinical scales were selected according to a published protocol for upper limb robotic rehabilitation [41].

\section{Equipment}

Amadeo (Tyromotion, Austria) is a robot specifically design for hand rehabilitation (see Fig. 1). It is is an endeffector robot, with 5 degrees of freedom (DOF). It provides the motion of one or all five fingers, thanks to a passive rotational joint placed between fingertip and an entity moving laterally (the thumb has got two passive rotational joints). All five translational DOFs are independent and provide large coverage of the finger workspace. The set-up involved securing a small magnetic disc to the pulp of each finger with adhesive tape for connection with the end-effector, which would move back and forth within sliders aligned with the finger movement direction. The wrist is immobilized using a Velcro strap so that the elbow and shoulder are inhibited from moving. The robot can calibrate the full passive range of motion (pROM) for each finger before the start of a session, and supply the assistive force to patients to complete the remaining range of motion during an exercise. Moreover, the maximum flexion and extension force for each finger are recorded to calibrate the exercise when a strength control is required [36].

\section{Robotic assessment}

By means of Amadeo, three different evaluations were carried out: force assessment, muscle tone assessment and spasticity assessment. Before starting the assessment, the pROM for each finger and the thumb are recorded for each individual subject (Fig. 2 a-c).

\section{Force assessment}

The force assessment program measures the patient's isometric strength for each finger separately and the hand strength. First, the sliders independently move the fingers to the middle position ( $50 \%$ of the pROM, Fig. 2 b). Then, the subject is asked to flex and then to extend his/her fingers as much as possible, while the sliders are blocked. The device measures continuously the force

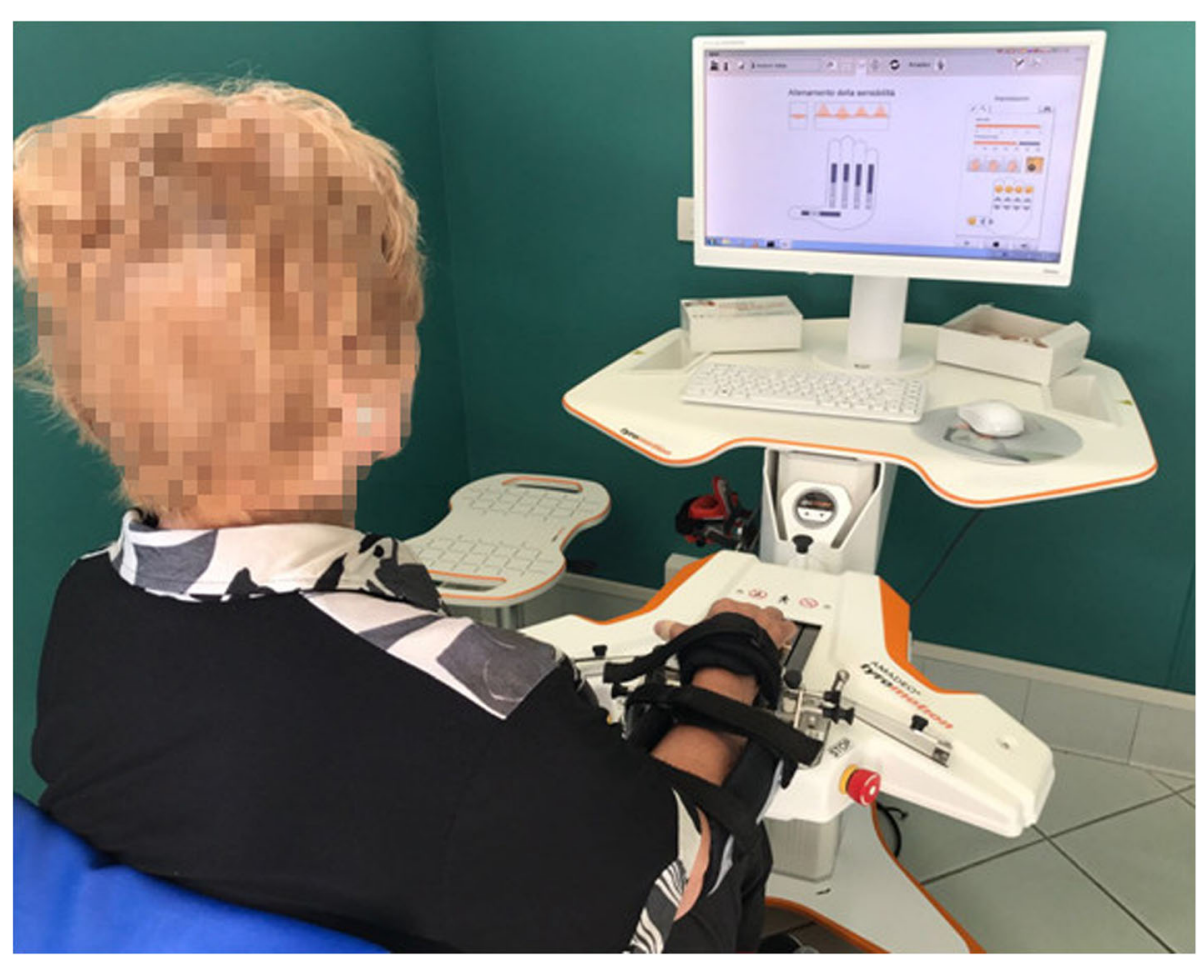

Fig. 1 The Amadeo device (Tyromotion) 

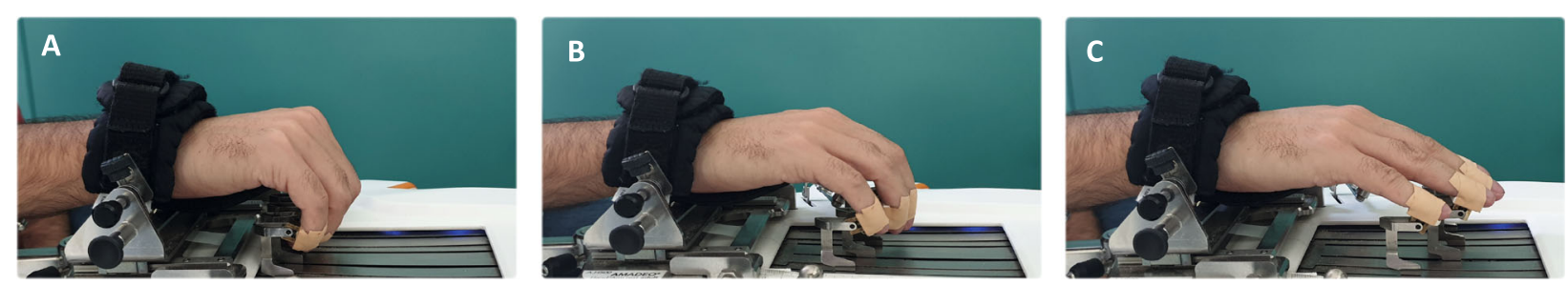

Fig. 2 Different positions of the fingers during the tests: maximum flexion (a), middle position (b) and maximum extension(c)

exerted, in both directions by each finger. Finally, the device provides, for flexion and extension separately: the maximum force values independently achieved by each finger; (b) the maximum value of the hand force (obtained as sum of the forces simultaneously exerted by each finger). The latter were referred as HandForce flex $_{\text {}}$

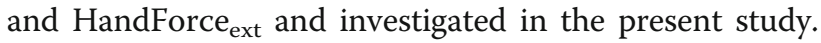
During the test, the physical therapist stimulated the subject to flex and then to extend the fingers as much as possible.

\section{Muscle tone assessment}

The muscle tone assessment measures the passive baseline force of the finger muscles. The finger sliders move to the middle position (Fig. $2 \mathrm{~b}$ ). After starting the measurement, the patient tries to keep the fingers as still and relaxed as possible, while the device measures the force exerted by each finger. The measurement lasts $5 \mathrm{~s}$. Before the test, the physical therapist stimulated the subject to relax his/her fingers, while no specific feedback was given during the test.

\section{Spasticity assessment}

For the spasticity assessment, the fingers can be moved with three varying speeds, which allows a spasticity evaluation based on the Modified Ashworth Scale (MAS) and the Modified Tardieu Scale (MTS). The finger sliders move each finger to the respective starting position, as measured during the baseline pROM assessment. Then, fingers are moved across the entire pROM with three different velocities: V1 (slow), V2 (medium) and V3 (fast). Velocities are set in a way, that all fingers start and arrive at the same time (i.e. the finger with the shortest ROM moves slower than the finger with the largest $\mathrm{ROM})$. V1, V2, and V3 related to the finger with the biggest ROM as follows: V1 $=0.01 \mathrm{~m} / \mathrm{s} ; \mathrm{V} 2=0.05 \mathrm{~m} /$ $\mathrm{s}$; and V3 $=0.1 \mathrm{~m} / \mathrm{s}$. Before the test, the physical therapist stimulated the subject to relax his/her fingers, while no specific feedback was given during the test. According to the clinical measures of spasticity (MAS and Tardieu Scale), the following values are provided: MAS (one value for each velocity); MTS (one value for each velocity); R2 (the full range of motion, calculated at V1, and expressed as percentage of the pROM); R1 (the angle of muscle reaction to the stretch, calculated at V2 and V3, and expressed as percentage of the pROM); the difference R2-R1; a single evaluation for each finger, as well as a total evaluation for the four fingers are provided. In the current study, the MAS and the MTS values, at $\mathrm{V} 1$ and $\mathrm{V} 3$, were investigated (namely $\mathrm{MAS}_{\mathrm{V} 1}$, $\left.\mathrm{MAS}_{\mathrm{V} 3}, \mathrm{MTS}_{\mathrm{V} 1}, \mathrm{MTS}_{\mathrm{V} 3}\right)$.

\section{Experimental protocol}

In our study, each participant was asked to perform each investigated assessment provided by the device three times. Specifically, to avoid the onset of spasticity due to the maximum contractions, the order of the tests was the following: 1) muscle tone (three repetitions); 2) spasticity (three repetitions); 3) strength (three repetitions). For each subject, a session lasted between 5 and $10 \mathrm{~min}$, depending on patient's impairment and compliance. In each rehabilitation center, the robotic assessment was performed by a single physical therapist, proficient in the use of the device. Before starting the study, the procedures were harmonized among centers.

Both patients and healthy subjects were tested twice, 1 day apart, to assess the test-retest reliability of the provided outcome measures. Each subject was evaluated in the two sessions by the same operator, using the pROM recorded in the first evaluation. For both test sessions, the value of each measure obtained in the three repetitions was recorded. With respect to the numeric data (i.e., HandForce flex $_{\text {, HandForce }}$ ext and Muscle tone), the mean value was computed and used for the statistical analysis. With respect to the ordinal data $\left(\mathrm{MAS}_{\mathrm{V} 1}\right.$, $\mathrm{MAS}_{\mathrm{V} 3}, \mathrm{MTS}_{\mathrm{V} 1}, \mathrm{MTS}_{\mathrm{V} 3}$ ), the best value (i.e., the lowest value) was used.

\section{Statistical analysis \\ Test-retest reliability}

Test-retest reliability of the numeric data was assessed by using the Intraclass Correlation Coefficient (ICC), using a two-way mixed effect, absolute agreement, multiple measurements model. Reliability was classified as excellent (ICC $>0.90)$, good $(0.75<\mathrm{ICC} \leq 0.90)$, moderate $(0.5<\mathrm{ICC} \leq 0.75)$ or poor otherwise [42]. Absolute test-retest reliability was analyzed comparing for each index data obtained during the two test sessions by 
mean of Wilcoxon signed-rank test and Bland-Altman plots. To estimate the response stability, standard errors of measurement (SEM) and minimum detectable changes (MDC) were also calculated. The SEM were calculated using the mean of the standard deviations (SD) of data obtained at the two paired sessions and the ICC with the following formula:

$$
S E M=S D_{\text {mean }} \times \sqrt{1-I C C}
$$

while the MDC values were computed using the following formula:

$$
M D C=1.96 \times S E M \times \sqrt{2} .
$$

\section{Concurrent validity}

To assess the concurrent validity of the robotic indices, the correlations between the robotic parameters and the clinical scales were investigated using the Spearman's rank correlation coefficients. The coefficient values were interpreted as follows [43]: $0.0-0.2$ little if any; 0.2-0.4 weak; 0.4-0.7 moderate; $0.7-1.0$ strong.

\section{Discriminant ability}

The ability of the robotic indices to discriminate stroke patients from healthy subjects was evaluated by means of the Mann-Whitney U test.

Statistical analysis was performed using SPSS (version 25, SPSS Inc., Chicago IL, USA) and MedCalc (version 14, MedCalc Software, Ostend, Belgium). A $p$-value lower than 0.05 was deemed significant. The false discovery rate method [44] was used to adjust for multiple comparisons.

\section{Results}

\section{Test-retest reliability}

ICCs and 95\% confidence intervals in patients with stroke, as well as the results of the statistical analysis of the comparison of the two assessments, performed one day apart, are shown in Table 2. Due to clinical reasons, two patients did not perform the retest evaluation. Moreover, due to technical reasons, force and muscle tone data were missing in three and five patients, respectively. Therefore, test-retest reliability was computed using all the available data for each measure (98.3, 95.8 and $94.2 \%$ of data for spasticity, strength and muscle tone, respectively). The HandForce ${ }_{\text {ext }}$, the HandForce ${ }_{\text {flex }}$, and the muscle tone showed an excellent reliability (ICC >0.9), see Fig. 3, while the MAS and the MTS values showed a poor reliability (ICCs lower than 0.5 for both V1 and V3). With respect to the absolute reliability, only the muscle tone showed a statistical significant increase in the retest, when compared to the test, with a mean increase lower than $2 \mathrm{~N}$. The Bland-Altman plots, with the bias between the two assessments and the limits of agreement for each measure with a good reliability, are reported in Fig. 4.

With respect to the healthy subjects (Table 3), a good reliability was found for the HandForce ${ }_{\mathrm{ext}}$, the HandFor$\mathrm{ce}_{\text {flex }}$, the muscle tone and the $\mathrm{MAS}_{\mathrm{V} 3}$; a moderate reliability for the $M A S_{V 1}$; a poor reliability for $M_{T S}$ and $\mathrm{MTS}_{\mathrm{V} 3}$. In Table 2 and Table 3 are also reported the SEM and the MDC for all the investigated measures, for stroke patients and healthy subjects, respectively. In stroke patients, MDC values were of $10.6 \mathrm{~N}$ for HandForce $_{\text {flex }}, 3.4 \mathrm{~N}$ for HandForce ext, $14.3 \mathrm{~N}$ for muscle tone; for MAS and MTS, MDC values ranged from 3 to 3.4 points.

\section{Concurrent validity}

The results of the correlation analysis between the robotic measures and the clinical scales are reported in Table 4. Both the HandForce flex $_{\text {and }}$ and HandForce ${ }_{\text {ext }}$ showed a strong correlation with the clinical measures of strength $\left(\mathrm{MRC}_{\text {flex }}\right.$ and $\left.M R C_{\text {ext }}\right)$ and a moderate correlation with the FAT. On the contrary, we did not find a significant correlation neither between muscle tone

\begin{tabular}{|c|c|c|c|c|c|c|c|c|c|}
\hline & \multirow[t]{2}{*}{$\mathrm{N}$} & \multirow{2}{*}{$\begin{array}{l}\text { Test Mean } \\
\text { (SD) }\end{array}$} & \multirow{2}{*}{$\begin{array}{l}\text { Retest } \\
\text { Mean (SD) }\end{array}$} & \multirow[t]{2}{*}{ ICC } & \multicolumn{2}{|l|}{$95 \% \mathrm{Cl}$} & \multirow[t]{2}{*}{$P$} & \multirow[t]{2}{*}{ SEM } & \multirow[t]{2}{*}{ MDC } \\
\hline & & & & & Lower bound & Upper bound & & & \\
\hline HandForce $_{\text {ext }}(\mathrm{N})$ & 115 & $5.7(8.2)$ & $5.9(7.8)$ & 0.977 & 0.967 & 0.984 & 0.365 & 1.2 & 3.4 \\
\hline HandForce $_{\text {flex }}(\mathrm{N})$ & 115 & $22.1(26.8)$ & $21.5(26.0)$ & 0.979 & 0.969 & 0.985 & 0.467 & 3.8 & 10.6 \\
\hline Muscle tone $(\mathrm{N})^{+}$ & 113 & $-12.0(16.6)$ & $-13.9(17.1)$ & 0.906 & 0.860 & 0.937 & 0.048 & 5.2 & 14.3 \\
\hline $\mathrm{MAS}_{\mathrm{V} 1}$ & 118 & $1.2(1.6)$ & $1.2(1.5)$ & 0.473 & 0.240 & 0.634 & 0.960 & 1.1 & 3.1 \\
\hline $\mathrm{MTS}_{\mathrm{V} 1}$ & 118 & $0.8(1.5)$ & $0.9(1.5)$ & 0.396 & 0.129 & 0.581 & 0.725 & 1.2 & 3.2 \\
\hline $\mathrm{MAS}_{\mathrm{V} 3}$ & 118 & $1.6(1.5)$ & $1.7(1.5)$ & 0.486 & 0.257 & 0.644 & 0.606 & 1.1 & 3.0 \\
\hline $\mathrm{MTS}_{\mathrm{V}_{3}}$ & 118 & $0.9(1.4)$ & $1.0(1.5)$ & 0.268 & -0.057 & 0.494 & 0.424 & 1.2 & 3.4 \\
\hline
\end{tabular}

Table 2 Test-retest reliability in patients with stroke

SD Standard Deviation; ICC Intraclass Correlation Coefficient; Cl Confidence Interval. SEM Standard Error of Measurement; MDC Minimal Detectable Change. Pvalues in bold indicate statistical significance of the Wilcoxon signed-rank test (P lower than 0.05$).{ }^{\dagger}$ Negative values: flexor muscles tone. Positive values: extensor muscles tone 

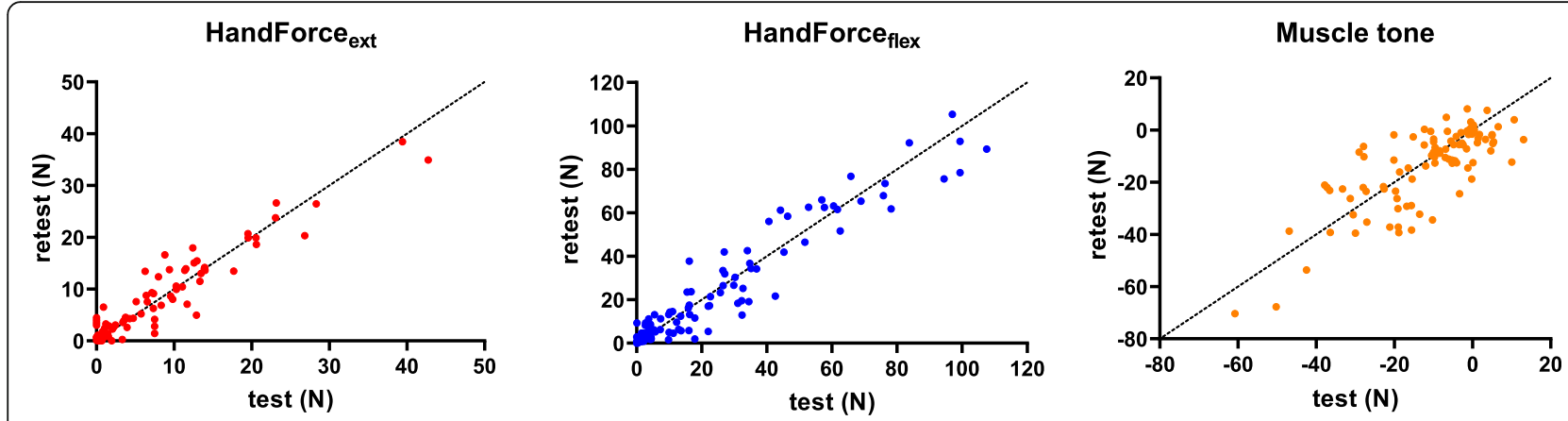

Fig. 3 Scatterplot of the three robotic measures showing good reliability

and the MAS, nor between the robotic and the clinical assessment of spasticity.

\section{Discriminant ability}

The expected ability of the robotic indices to distinguish between patients with stroke and healthy subjects was confirmed by the results of the statistical analysis. In fact, all the robotic indices obtained from patients were statistically different from those of controls (see Table 5), with $p<0.001$.

\section{Discussion}

In this study, we assessed the between-day test-retest reliability and the validity of the outcome measures provided by a robotic device for finger training in a sample of patients with subacute stroke, and their ability to differentiate patients from a group of age-matched healthy subjects. The above mentioned outcome measures assess finger strength, both in flexion and in extension, muscle tone at rest, and spasticity measured at different speeds. It is worthy to note that a lower number of studies investigated hand strength, compared to other joint (as shoulder, elbow, knee [45]).

\section{Strength assessment}

Our results showed that both measures of strength (in flexion and in extension), as well as the muscle tone, are characterized by an excellent reliability, with ICC values higher than 0.9 , indicating that they could be used for intra-individual comparisons (i.e. for individual decisionmaking) and not just for group-level comparisons (i.e. for the evaluation of a whole large group of patients), where an ICC value of 0.7 level is acceptable. Moreover, as showed by the statistical analysis, no bias was detected for the measure of strength. Finally, our MDCs, i.e., the minimal change needed to be confident at $95 \%$ that the observed change is true, are 10.6 and $3.4 \mathrm{~N}$ for flexion and extension force, respectively. This means that a difference in score higher of the above mentioned values can be interpreted as a change in patient's finger strength, and not due to the measurement error. Our results are in accordance with the previous studies on the same subject. In fact, literature data confirmed that hand strength measures are reliable in patients with stroke. Comparing our results to those already published, obtained with different instrument, we found similar ICCs, and lower (i.e., better) MDCs. Specifically, Bertrand et al. [46], evaluating grip strength in a sample with stroke in the first weeks after a stroke, using a Jamar dynamometer, found ICC ranging from 0.97 to 0.99 , and MDC ranging from 2.73 to $4.68 \mathrm{~kg}$. Similarly, Chen et al. [47] investigated the test-retest reproducibility of 3 hand strength tests (grip, palmar pinch, and lateral pinch) both in patients with a recent stroke (onset $<6$ months) and in

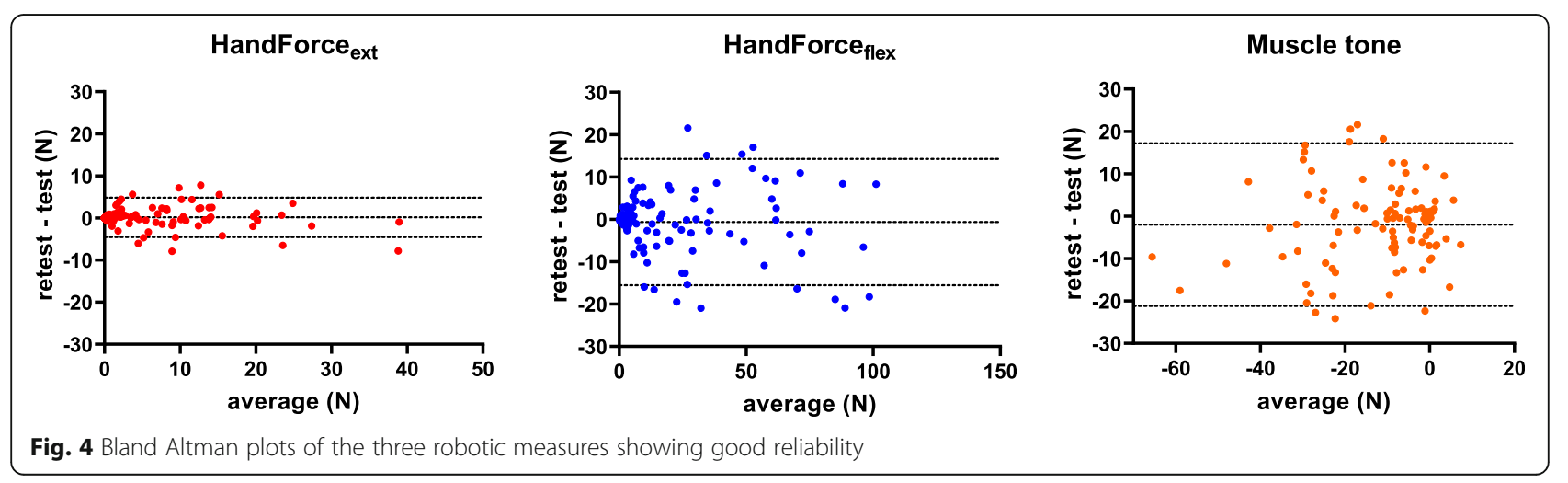


Table 3 Test-retest reliability in healthy subjects $(N=40)$

\begin{tabular}{|c|c|c|c|c|c|c|c|c|}
\hline & & Retest & ICC & $95 \% \mathrm{Cl}$ & & $P$ & SEM & MDC \\
\hline & $\begin{array}{l}\text { Mean } \\
\text { (SD) }\end{array}$ & $\begin{array}{l}\text { Mean } \\
\text { (SD) }\end{array}$ & & Lower bound & Upper bound & & & \\
\hline HandForce $_{\text {ext }}(\mathrm{N})$ & $29.4(6.7)$ & $29.8(7.1)$ & 0.735 & 0.489 & 0.863 & 0.338 & 3.6 & 9.8 \\
\hline HandForce $_{\text {flex }}(\mathrm{N})$ & 91.4 (19.5) & $92.5(20.1)$ & 0.888 & 0.784 & 0.942 & 0.388 & 6.6 & 18.3 \\
\hline Muscle tone $(\mathrm{N})^{\dagger}$ & $-0.2(0.4)$ & $-0.2(0.5)$ & 0.839 & 0.689 & 0.917 & 0.161 & 0.2 & 0.5 \\
\hline $\mathrm{MAS}_{\mathrm{V} 1}$ & $0.12(0.35)$ & $0.31(0.8)$ & 0.657 & 0.356 & 0.819 & 0.041 & 0.3 & 0.9 \\
\hline $\mathrm{MTS}_{\mathrm{V} 1}$ & $0.00(0.00)$ & $0.10(0.5)$ & 0.000 & -0.880 & 0.472 & 0.18 & 0.5 & 1.4 \\
\hline $\mathrm{MAS}_{\mathrm{V} 3}$ & $0.4(0.7)$ & $0.5(1.0)$ & 0.849 & 0.712 & 0.921 & 0.474 & 0.3 & 1.0 \\
\hline $\mathrm{MTS}_{\mathrm{V} 3}$ & $0.1(0.3)$ & $0.2(0.6)$ & 0.275 & -0.362 & 0.617 & 0.197 & 0.4 & 1.0 \\
\hline
\end{tabular}

SD Standard Deviation; ICC Intraclass Correlation Coefficient; CI Confidence Interval. SEM Standard Error of Measurement; MDC Minimal Detectable Change. Pvalues in bold indicate statistical significance of the Wilcoxon signed-rank test (P lower than 0.05$)$. ${ }^{+}$Negative values: flexor muscles tone. Positive values: extensor muscles tone

chronic stroke (onset $>6$ months), resulting in ICCs ranging from 0.85 to 0.98 ., while the MDCs for the more/less affected hand were $2.9 / 4.7 \mathrm{~kg}$ for the grip test, $1.2 / 1.3 \mathrm{~kg}$ for the palmar pinch test, and $1.4 / 1.0 \mathrm{~kg}$ for the lateral pinch test. Boissy et al. [48] assessed the maximal voluntary grip force with a modified strain gauge dynamometer in 15 chronic stroke subjects and 10 control subjects, obtaining an ICC $>0.86$ and a SEM of $25 \mathrm{~N}$.

Moreover, as expected, patients with stroke showed a strength impairment, both in flexion and in extension. The measures of strength were also well correlated with the corresponding clinical measures of strength, confirming that they provide meaningful information from a clinical point of view. In addition, the correlation with the Frenchay Arm test confirm that the weakness of hand in stroke patients reflects a reduction of upper extremity proximal motor control and dexterity during activity of daily living. The obtained results about the finger strength (high reliability, low MDC, correlation with clinical scales) are very important from a clinical point of view, given the importance of a correct assessment of finger strength, not only to assess the effect of a treatment, either robotic or conventional, but also to tailor the treatment itself, on the basis of the initial status of the patients. In fact, several

Table 4 Validity (correlations with clinical scales)

\begin{tabular}{lllll}
\hline & MRC (ext) & MRC (flex) & FAT & MAS \\
\hline HandForce $_{\text {ext }}$ & $0.710^{* * *}$ & $0.732^{* * *}$ & $0.533^{* * *}$ & 0.074 \\
HandForce flex $^{*}$ & $0.705^{* * *}$ & $0.713^{* * *}$ & $0.550^{* * *}$ & 0.156 \\
Muscle tone $^{\dagger}$ & -0.05 & -0.046 & -0.066 & -0.144 \\
MAS $_{\text {V1 }}$ & 0.084 & 0.103 & 0.042 & -0.037 \\
MTS $_{V 1}$ & 0.029 & 0.059 & 0.013 & 0.009 \\
MAS $_{\text {V3 }}$ & 0.111 & 0.091 & 0.089 & 0.024 \\
MTS $_{\text {V3 }}$ & 0.081 & 0.064 & 0.107 & -0.040 \\
\hline Con $^{*}$
\end{tabular}

Correlations between robotic indices and clinical scales are assessed by means of Spearman's correlation coefficients. MRC Medical Research Council; FAT Frenchay Arm Test; MAS Modified Ashworth Scale. The symbol *** indicates a $P$-value (corrected for multiple comparison, by using a False Discovery Rate procedure) lower than 0.001 studies highlighted the importance of finger strength as a predictor of recovery in stroke patients [49-53] and, therefore, to obtain crucial information to manage the rehabilitation pathway.

\section{Muscle tone at rest}

With respect to the muscle tone measurement, we found an excellent reliability, as showed by the ICC value, equal to 0.906 . This results is of particular importance, because in patients with upper limb dysfunction following stroke, hypertonicity is a common problem that can contribute to impaired movement patterns and result in significant activity limitations; moreover, usually in the upper limb, flexor muscles are more commonly involved distally [54], supporting the importance of an instrumented assessment for the muscle tone at the hand. In particular, the clinical efficacy of treatments for spasticity would be further improved if the spasticity assessments are more reliable and accurate [55].

Table 5 Discriminant ability (differences between patients with stroke and healthy subjects)

\begin{tabular}{|c|c|c|c|c|c|}
\hline & \multirow{2}{*}{$\begin{array}{l}\text { Mean } \\
\text { difference } \\
\text { (patients - } \\
\text { healthy) }\end{array}$} & \multirow{2}{*}{$\begin{array}{l}\text { SE } \\
\text { difference }\end{array}$} & \multicolumn{2}{|l|}{$95 \%$ SE } & \multirow[t]{2}{*}{$P^{*}$} \\
\hline & & & Lower & Upper & \\
\hline HandForce $_{\text {ext }}$ & $-23,4$ & 1,5 & $-26,3$ & $-20,4$ & $<0.001$ \\
\hline HandForce $_{\text {flex }}$ & $-68,3$ & 4,8 & $-77,7$ & $-58,9$ & $<0.001$ \\
\hline Muscle tone $(\mathrm{N})$ & $-13,8$ & 3,6 & $-20,9$ & $-6,8$ & $<0.001$ \\
\hline $\mathrm{MAS}_{\mathrm{V} 1}$ & 1,1 & 0,3 & 0,6 & 1,6 & $<0.001$ \\
\hline $\mathrm{MTS}_{\mathrm{V} 1}$ & 0,8 & 0,2 & 0,3 & 1,3 & $<0.001$ \\
\hline $\mathrm{MAS}_{\mathrm{V} 3}$ & 1,2 & 0,3 & 0,7 & 1,7 & $<0.001$ \\
\hline $\mathrm{MTS}_{\mathrm{V} 3}$ & 0,8 & 0,2 & 0,3 & 1,2 & $<0.001$ \\
\hline \multicolumn{6}{|c|}{$\begin{array}{l}\text { Comparison between patients with stroke and healthy subjects are assessed } \\
\text { by means of the Mann-Whitney U test. SE Standard error. Values in bold } \\
\text { indicate statistical significance ( } p \text { lower than } 0.05 \text { ) } \\
{ }^{+} \text {The negative value means a higher tone of flexor muscles in patients with } \\
\text { stroke, when compared with healthy subjects } \\
\text { * Corrected for multiple comparison, by using a False Discovery }\end{array}$} \\
\hline
\end{tabular}


In stroke patients, the muscle tone was not correlated with the MAS: however, this result is unsurprising because of (a) the very low variation of the MAS in the analyzed sample $(73.1 \%$ of patients were clinically rated between 0 and 1); (b) the different assessment, i.e., at rest vs movement, that can lead to different results; and (c) the known low metrological characteristics of the scale itself [56].

\section{Spasticity}

Finally, spasticity measures, i.e. the MAS and the MTS, at both low and high velocity, showed unsatisfactory results from a psychometric point of view. In fact, even if a significant difference with the healthy subjects was found, our results indicate that their reliability was poor, and, in addition, they do not show meaningful correlation with the clinical scale (i.e., the MAS clinically evaluated). With respect to the lack of correlation with the clinical assessment, our results are in accordance with those already reported in literature, where instrumental assessments of spasticity usually appear uncorrelated with the clinical counterparts [57-59]. In fact, the psychometric properties of the clinical assessment of spasticity are very low [60] and, therefore, they cannot act as golden standard, supporting the search of new tools to objectively quantify the spasticity. Conversely, referring to the ICC values, these results differ from some published studies: Centen et al. [61] using a robotic exoskeleton for the upper limb to evaluated the spasticity at elbow, found intra-class correlations that varied, depending on parameter, from 0.66 to 0.95 ; Condliffe et al. [62], recording biceps brachii and brachioradialis EMG and torque during passive ramp-and-hold elbow flexion, obtained ICC ranging from 0.63 to 0.85 . Calota et al. [63], using a portable device, found ICCs from 0.46 to 0.68 .

These differences can be explained by several argumentations. First of all, none of the previous studies investigated the finger spasticity; additionally, most of the studies employed both mechanical and neurophysiological measures [60]; moreover, previous studies investigated, as measure of spasticity, mechanical (as torque) or neurophysiological (as EMG burst) measures, not an ordinal measure of spasticity; finally, their cohort comprised stroke patients in the chronic phase, where spasticity is higher and the general conditions of patients are more stable. With respect to the latter aspect, it is worth noting that spasticity, as measured by the MAS, in our sample was low and with low variability across the patients, and this can be considered a limitation of the study. Another limitation is the absence of the evaluation of the responsiveness to treatment of the investigated robotic measures.

\section{Conclusion}

We found that, in a sample of patients with stroke in the subacute phase, the measures of finger flexion and extension strength, provided by a robotic device for finger training are reliable, sensitive and strongly correlated with the clinical scales. Moreover, the measure of muscle tone at rest showed an excellent reliability. Therefore, they can be used as an evaluation tool that can be usefully integrated with the clinical evaluation. Conversely, in the investigated sample, the measures of spasticity did not show similar properties. The instrumental outcome measures are very important to have an objective and easy evaluation, as well as a guide to address the treatment path.

\section{Abbreviations}

ADL: Activities of Daily Living; FAT: Frenchay Arm test; ICC: Intraclass Correlation Coefficient; MAS: Modified Ashworth Scale; MDC: Minimum Detectable Change; MRC: Medical Research Council; MTS: Modified Tardieu Scale; pROM: Full passive Range of Motion; r: Spearman's correlation coefficient; SEM: Standard Error of Measurement

\section{Acknowledgements}

FDG Robotic Rehabilitation Group members:

Roma (RM): Irene Aprile, Marco Germanotta, Arianna Cruciani, Cristiano Pecchioli, Simona Loreti, Stefania Lattanzi, Laura Cortellini, Dionysia Papadopoulou, Serena Marsan, Chiara Di Blasi, Giuliana Liberti, Francesca Panzera, Piera Mitrione, Dario Ruzzi, Giuliana Rinaldi, Camilla Galli, Sabina Insalaco. Milano (MI): Angelo Montesano, Cristina Grosso, Paola Ammenti, Davide Cattaneo, Luca Azzinnaro, Daniela Barbieri, Silvia Cassani, Chiara Corrini, Matteo Meotti, Riccardo Parelli, Albino Spedicato, Marta Zocchi, Marcella Loffi, Domitilla Manenti, Laura Negri, Furio Gramatica, Valerio Gower. Rovato (BS): Silvia Galeri, Fulvia Noro, Luca Medici, Romina Garattini, Federica Bariselli, Marin Luli, Vera Rota, Mauro Ricca, Gianluigi Sacella, Stefano Negrini. Firenze (FI): Francesco Converti, Assunta Pizzi, Catuscia Falsini, Antonella Romanelli, Gabriella De Luca, Federica Vannetti, Elisabetta Simoncini, Monica Martini, Elisa Peccini. Fivizzano (MS): Francesca Cecchi, Lucia Avila, Maria Assunta Gabrielli, Manuele Barilli, Giorgia Giannarelli, Andrea Bertolini, Chiara Sarti, Emanuela Romano. Sant'Angelo dei Lombardi (AV): Fabio De Santis, Gabriele Speranza, Massimo Colella, Rita Mosca, Gaetanina Competiello, Antonietta Chiusano, Antonella Della Vecchia, Soriano Pasqualina, Michela Pagliarulo.

\section{Authors' contributions}

MG: Concept and design, acquisition of data, analysis and interpretation of data, preparation of manuscript; VG, FV: data analysis; DP, AC, CP, RM: acquisition and interpretation of data; GS, CF, FC, AM, SG: patients' recruitment, interpretation of data; FG: Concept and design, analysis and interpretation of data; IA: Concept and design, analysis and interpretation of data, preparation of manuscript; FDG_RRG: patients' recruitment, acquisition of data. All authors read and approved the final manuscript.

\section{Funding}

There were no funding sources for this research.

\section{Availability of data and materials}

The dataset used and/or analyzed during the current study available from the corresponding author on reasonable request.

\section{Ethics approval and consent to participate}

The present study was approved by the institutional ethics committee (FDG_6.4.2016). All participants provided written informed consent in accordance with ethical guidelines.

Consent for publication

Not applicable.

Competing interests

The authors declare that they have no competing interests. 


\section{Author details}

'IRCCS Fondazione Don Carlo Gnocchi, Via di Scandicci, 269, 50143 Florence, Italy. ${ }^{2}$ IRCCS Fondazione Don Carlo Gnocchi, Piazzale Morandi 6, 20121 Milan, taly.

\section{Received: 1 July 2019 Accepted: 12 December 2019}

Published online: 03 January 2020

\section{References}

1. Dobkin BH. Rehabilitation after stroke. N Engl J Med. 2005;352:1677-84.

2. Chu C-Y, Patterson RM. Soft robotic devices for hand rehabilitation and assistance: a narrative review. J Neuroeng Rehabil. 2018;15:9.

3. Bonifer N, Anderson KM. Application of constraint-induced movement therapy for an individual with severe chronic upper-extremity hemiplegia. Phys Ther. 2003:83:384-98.

4. Nakayama $\mathrm{H}$, Jørgensen $\mathrm{HS}$, Raaschou HO, Olsen TS. Recovery of upper extremity function in stroke patients: the Copenhagen stroke study. Arch Phys Med Rehabil. 1994;75:394-8.

5. Bonifer NM, Anderson KM, Arciniegas DB. Constraint-induced movement therapy after stroke: efficacy for patients with minimal upper-extremity motor ability. Arch Phys Med Rehabil. 2005;86:1867-73.

6. Yue Z, Zhang X, Wang J. Hand rehabilitation robotics on Poststroke motor recovery. Behav Neurol. 2017;2017:1-20.

7. Franck JA, Smeets RJEM, Seelen HAM. Changes in arm-hand function and arm-hand skill performance in patients after stroke during and after rehabilitation. PLoS One. 2017;12:e0179453 Tremblay F, editor.

8. Mehrholz J, Pohl M, Platz T, Kugler J, Elsner B. Electromechanical and robotassisted arm training for improving activities of daily living, arm function, and arm muscle strength after stroke. Cochrane Database Syst Rev. 2018;9:CD006876.

9. Masiero S, Poli P, Rosati G, Zanotto D, losa M, Paolucci S, et al. The value of robotic systems in stroke rehabilitation. Expert Rev Med Devices. 2014.

10. Gassert R, Dietz V. Rehabilitation robots for the treatment of sensorimotor deficits: a neurophysiological perspective. J Neuroeng Rehabil. 2018;15:46.

11. Lum PS, Godfrey SB, Brokaw EB, Holley R, Nichols D. Robotic approaches for rehabilitation of hand function after stroke. Am J Phys Med Rehabil. 2012;91:S242-54

12. Susanto EA, Tong RKY, Ockenfeld C, Ho NSK. Efficacy of robot-assisted fingers training in chronic stroke survivors: a pilot randomized-controlled trial. J Neuroeng Rehabil. 2015;12:42.

13. McConnell A, Moioli R, Brasil F, Vallejo M, Corne D, Vargas P, et al. Robotic devices and brain-machine interfaces for hand rehabilitation post-stroke. J Rehabil Med. 2017;49:449-60.

14. Hesse S, Kuhlmann H, Wilk J, Tomelleri C, Kirker SGB. A new electromechanical trainer for sensorimotor rehabilitation of paralysed fingers: a case series in chronic and acute stroke patients. J Neuroeng Rehabil. 2008:5:21.

15. Dovat L, Lambercy O, Gassert R, Maeder T, Milner T, Leong TC, et al. HandCARE: a cable-actuated rehabilitation system to train hand function after stroke. IEEE Trans Neural Syst Rehabil Eng. 2008;16:582-91.

16. Adamovich SV, Mathai A, Fluet GG, Qiu Q, Lewis J, Merians AS. Design of a complex virtual reality simulation to train finger motion for persons with hemiparesis: A proof of concept study. J Neuroeng Rehabil. 2009:6:28.

17. Tong KY, Ho SK, Pang PMK, Hu XL, Tam WK, Fung KL, et al. An intention driven hand functions task training robotic system. Conf Proc IEEE Eng Med Biol Soc. 2010:2010:3406-9.

18. Rowe JB, Chan V, Ingemanson ML, Cramer SC, Wolbrecht ET, Reinkensmeyer DJ. Robotic assistance for training finger movement using a Hebbian model: a randomized controlled trial. Neurorehabil Neural Repair. 2017;31:769-80.

19. Takahashi CD, Der-Yeghiaian L, Le V, Motiwala RR, Cramer SC. Robot-based hand motor therapy after stroke. Brain. 2008;131:425-37.

20. Orihuela-Espina F, Roldán GF, Sánchez-Villavicencio I, Palafox L, Leder R, Sucar LE, et al. Robot training for hand motor recovery in subacute stroke patients: a randomized controlled trial. J Hand Ther. 2016:29:51-7.

21. Sale P, Mazzoleni S, Lombardi V, Galafate D, Massimiani MP, Posteraro F, et al. Recovery of hand function with robot-assisted therapy in acute stroke patients: a randomized-controlled trial. Int J Rehabil Res Int Zeitschrift für Rehabil Rev Int Rech réadaptation. 2014;37:236-42

22. Calabrò RS, Accorinti M, Porcari B, Carioti L, Ciatto L, Billeri L, et al. Does hand robotic rehabilitation improve motor function by rebalancing interhemispheric connectivity after chronic stroke? Encouraging data from a randomised-clinical-trial. Clin Neurophysiol. 2019;130:767-80.

23. Germanotta M, Cruciani A, Pecchioli C, Loreti S, Spedicato A, Meotti M, et al. Reliability, validity and discriminant ability of the instrumental indices provided by a novel planar robotic device for upper limb rehabilitation. J Neuroeng Rehabil. BioMed Central. 2018;15:39.

24. Dipietro L, Krebs HI, Volpe BT, Stein J, Bever C, Mernoff ST, et al. Learning, not adaptation, characterizes stroke motor recovery: evidence from kinematic changes induced by robot-assisted therapy in trained and untrained task in the same workspace. IEEE Trans Neural Syst Rehabil Eng. 2012;20:48-57.

25. Mazzoleni S, Sale P, Tiboni M, Franceschini M, Carrozza MC, Posteraro F. Upper limb robot-assisted therapy in chronic and subacute stroke patients: A kinematic analysis. Am J Phys Med Rehabil. 2013;92:e26-37.

26. Coderre AM, Amr Abou Zeid AA, Dukelow SP, Demmer MJ, Moore KD, Demers MJ, et al. Assessment of Upper-Limb Sensorimotor Function of Subacute Stroke Patients Using Visually Guided Reaching. Neurorehabil Neural Repair. SAGE PublicationsSage CA: Los Angeles, CA; 2010;24:528-41.

27. Dukelow SP, Herter TM, Moore KD, Demers MJ, Glasgow Jl, Bagg SD, et al. Quantitative assessment of limb position sense following stroke. Neurorehabil Neural Repair. 2010;24:178-87.

28. Duret C, Courtial O, Grosmaire AG. Kinematic measures for upper limb motor assessment during robot-mediated training in patients with severe sub-acute stroke. Restor Neurol Neurosci. 2016:34:237-45.

29. Semrau JA, Herter TM, Scott SH, Dukelow SP. Inter-rater reliability of kinesthetic measurements with the KINARM robotic exoskeleton. J Neuroeng Rehabil. 2017;14.

30. Kenzie JM, Semrau JA, Hill MD, Scott SH, Dukelow SP. A composite robotic-based measure of upper limb proprioception. J Neuroeng Rehabil. England. 2017;14:114.

31. Pila O, Duret C, Gracies J-M, Francisco GE, Bayle N, Hutin É. Evolution of upper limb kinematics four years after subacute robot-assisted rehabilitation in stroke patients. Int J Neurosci Taylor \& Francis. 2018:1-10.

32. Ingemanson ML, Rowe JB, Chan V, Wolbrecht ET, Cramer SC, Reinkensmeyer DJ. Use of a robotic device to measure age-related decline in finger proprioception. Exp Brain Res. 2016;234:83-93.

33. Gilliaux M, Lejeune T, Detrembleur C, Sapin J, Dehez B, Selves C, et al. Using the robotic device REAplan as a valid, reliable, and sensitive tool to quantify upper limb impairments in stroke patients. J Rehabil Med. 2014:46:117-25.

34. Gilliaux M, Lejeune T, Detrembleur C, Sapin J, Dehez B, Stoquart G. A robotic device as a sensitive quantitative tool to assess upper limb impairments in stroke patients: a preliminary prospective cohort study. J Rehabil Med Medical Journals Limited. 2012:44:210-7.

35. Stein J, Bishop L, Gillen G, Helbok R. Robot-assisted exercise for hand weakness after stroke: a pilot study. Am J Phys Med Rehabil. 2011;90:887-94.

36. Hwang $\mathrm{CH}$, Seong JW, Son D-S. Individual finger synchronized robotassisted hand rehabilitation in subacute to chronic stroke: a prospective randomized clinical trial of efficacy. Clin Rehabil. 2012;26:696-704.

37. Aprile I, Germanotta M, Cruciani A, Loreti S, Pecchioli C, Cecchi F, et al. Upper limb robotic rehabilitation after stroke: a multicenter, randomized clinical trial. J Neurol Phys Ther. 2020:44:3-14.

38. Paternostro-Sluga T, Grim-Stieger M, Posch M, Schuhfried O, Vacariu G, Mittermaier C, et al. Reliability and validity of the Medical Research Council (MRC) scale and a modified scale for testing muscle strength in patients with radial palsy. J Rehabil Med. 2008;40:665-71.

39. Pandyan AD, Johnson GR, Price $\mathrm{Cl}$, Curless RH, Barnes MP, Rodgers $\mathrm{H}$. A review of the properties and limitations of the Ashworth and modified Ashworth scales as measures of spasticity. Clin Rehabil. 1999;13:373-83.

40. Heller A, Wade DT, Wood VA, Sunderland A, Hewer RL, Ward E. Arm function after stroke: measurement and recovery over the first three months. J Neurol Neurosurg Psychiatry. 1987;50:714-9.

41. Franceschini M, Colombo R, Posteraro F, Sale P. A proposal for an Italian minimum data set assessment protocol for robot-assisted rehabilitation: a Delphi study. Eur J Phys Rehabil Med. 2015;51:745-53.

42. Cicchetti DV. Guidelines, criteria, and rules of thumb for evaluating normed and standardized assessment instruments in psychology. Psychol Assess. 1994

43. Guilford, J. P. Fundamental statistics in psychology and education. New York (330 west 42nd street): McGraw-Hill book company, 1956. 565 P. \$6.25. Sci Educ. Wiley subscription services, Inc., A Wiley Company; 1957;41:244-244.

44. Benjamini $Y$, Hochberg Y. Controlling the FDR:a practical and powerful approach to multiple testing. J R Stat Soc Ser B. 1995;57:289-300.

45. Kristensen $\mathrm{OH}$, Stenager E, Dalgas U. Muscle Strength and Poststroke Hemiplegia: A Systematic Review of Muscle Strength Assessment and Muscle Strength Impairment. Arch Phys Med Rehabil. 2017.

46. Bertrand AM, Fournier K, Wick Brasey MG, Kaiser ML, Frischknecht R, Diserens K. Reliability of maximal grip strength measurements and grip strength recovery following a stroke. J Hand Ther. 2015;28:356-62. 
47. Chen HM, Chen CC, Hsueh IP, Huang SL, Hsieh CL. Test-retest reproducibility and smallest real difference of 5 hand function tests in patients with stroke. Neurorehabil Neural Repair. 2009;23:435-40.

48. Boissy P, Bourbonnais D, Carlotti MM, Gravel D, Arsenault BA. Maximal grip force in chronic stroke subjects and its relationship to global upper extremity function. Clin Rehabil. 1999;13:354-62.

49. Sunderland A, Tinson D, Bradley L, Langton HR. Arm function after stroke. An evaluation of grip strength as a measure of recovery and a prognostic indicator. J Neurol Neurosurg Psychiatry. 1989;52:1267-72.

50. Fritz SL, Light KE, Patterson TS, Behrman AL, Davis SB. Active finger extension predicts outcomes after constraint-induced movement therapy for individuals with hemiparesis after stroke. Stroke. 2005;36:1172-7.

51. Nijland RHM, EEH WW, Harmeling-Van Der Wel BC, Kwakkel G. Presence of finger extension and shoulder abduction within 72 hours after stroke predicts functional recovery: early prediction of functional outcome after stroke: the EPOS cohort study. Stroke. 2010;41:745-50.

52. Stinear CM, Barber PA, Petoe M, Anwar S, Byblow WD. The PREP algorithm predicts potential for upper limb recovery after stroke. Brain. 2012;135:2527-35.

53. Snickars J, Persson HC, Sunnerhagen KS. Early clinical predictors of motor function in the upper extremity one month post-stroke. J Rehabil Med. 2017:49:216-22.

54. Marciniak C. Poststroke Hypertonicity: upper limb assessment and treatment. Top Stroke Rehabil. 2011.

55. Wang H, Huang P, Li X, Samuel OW, Xiang Y, Li G. Spasticity Assessment Based on the Maximum Isometrics Voluntary Contraction of Upper Limb Muscles in Post-stroke Hemiplegia. Front Neurol Frontiers. 2019;10:465.

56. Fleuren JFM, Voerman GE, Erren-Wolters CV, Snoek GJ, Rietman JS, Hermens $\mathrm{HJ}$, et al. Stop using the Ashworth scale for the assessment of spasticity. J Neurol Neurosurg Psychiatry. 2009;81:46-52.

57. Jobin A, Levin MF. Regulation of stretch reflex threshold in elbow flexors in children with cerebral palsy: a new measure of spasticity. Dev Med Child Neurol. 2000;42:531-40.

58. Mullick AA, Musampa NK, Feldman AG, Levin MF. Stretch reflex spatial threshold measure discriminates between spasticity and rigidity. Clin Neurophysiol. 2013;124:740-51.

59. Germanotta M, Taborri J, Rossi S, Frascarelli F, Palermo E, Cappa P, et al. Spasticity measurement based on tonic stretch reflex threshold in children with cerebral palsy using the pediAnklebot. Front Hum Neurosci. 2017;11.

60. Bar-On L, Aertbeliën E, Molenaers G, Dan B, Desloovere K. Manually controlled instrumented spasticity assessments: a systematic review of psychometric properties. Dev Med Child Neurol. 2014.

61. Centen A, Lowrey CR, Scott SH, Yeh T-T, Mochizuki G. KAPS (kinematic assessment of passive stretch): a tool to assess elbow flexor and extensor spasticity after stroke using a robotic exoskeleton. J Neuroeng Rehabil. BioMed Central. 2017;14:59.

62. Condliffe EG, Clark DJ, Patten C. Reliability of elbow stretch reflex assessment in chronic post-stroke hemiparesis. Clin Neurophysiol. 2005.

63. Calota A, Feldman AG, Levin MF. Spasticity measurement based on tonic stretch reflex threshold in stroke using a portable device. Clin Neurophysiol. 2008;119:2329-37.

\section{Publisher's Note}

Springer Nature remains neutral with regard to jurisdictional claims in published maps and institutional affiliations.

Ready to submit your research? Choose BMC and benefit from:
- fast, convenient online submission
- thorough peer review by experienced researchers in your field
- rapid publication on acceptance
- support for research data, including large and complex data types
- gold Open Access which fosters wider collaboration and increased citations
- maximum visibility for your research: over 100M website views per year
At BMC, research is always in progress.
Learn more biomedcentral.com/submissions

